\title{
Diffuse interlobular septal thickening in a coal miner
}

\author{
S G Thrumurthy, S Kearney, M Sissons, Y Haider
}

Department of Respiratory Medicine, Chorley and South Ribble Hospital, Lancashire Teaching Hospitals NHS Foundation Trust, UK

Correspondence to:

Dr Y Haider, Department of Respiratory Medicine, Chorley and South Ribble Hospital, Lancashire Teaching Hospitals NHS Foundation Trust, Preston Road, Chorley PR7 1PP, UK: Yussef.Haider@|thtr.nhs.uk

Received 18 June 2009 Accepted 4 November 2009

\begin{abstract}
Diffuse interlobular septal thickening (DIST) is an abnormality seen on high-resolution CT (HRCT) scanning of the thorax. While DIST may be present to variable extents in a number of lung conditions, it is uncommon as a predominant finding except in a few entities. This report features an ex-coal miner, thought to have coal workers' pneumoconiosis (CWP), in whom the HRCT scan showed no evidence of CWP and instead showed DIST. The patient's condition progressed incessantly towards death from severe secondary pulmonary hypertension. The case links fatal pulmonary hypertension to DIST, a pattern not previously described in coal workers.
\end{abstract}

A 63-year-old man presented to a clinic with a 2year history of dyspnoea and cough. He was a lifelong non-smoker but had been a coal miner for 38 years with almost daily exposure at the coal face. Chest radiography and a CT scan of the thorax showed only minor "interstitial change" and spirometry showed only a mild obstructive defect. He was started on oral corticosteroids and sent for open lung biopsy. The biopsy, taken from the lingula, was non-diagnostic but revealed markedly thickened arteries with non-specific interstitial inflammation and fibrosis (fig 1) but no anthracosis. He was maintained on steroids (oral prednisolone $10 \mathrm{mg}$ daily) but remained breathless on follow-up. He developed postoperative recurrent pleural effusion on the side of the biopsy, requiring pleurodesis. An echocardiogram showed normal left ventricular function (no specific comment was made regarding the right heart). In view of the lack of clinical improvement, an opinion was sought from a respiratory unit where the patient had a high-resolution CT (HRCT) scan of the thorax and review of previous lung biopsy. Despite the atypical findings, he was felt to have a form of coal workers' pneumoconiosis (CWP) and he successfully claimed for Industrial Injuries Benefit. Although steroids had not improved his spirometry, he was maintained on prednisolone long term.

His symptoms progressed over the next few years with only a mild reduction in spirometry and lung volumes (table 1). However, diffusion studies showed a marked decline in transfer factor and transfer coefficient (table 1). A subsequent echocardiogram showed severe pulmonary hypertension (mean pulmonary arterial pressure $65 \mathrm{~mm} \mathrm{Hg}$; normal $<25 \mathrm{~mm} \mathrm{Hg}$ ) with a dilated right atrium and ventricle but normal left ventricular function. CT-pulmonary angiography (CTPA) excluded pulmonary emboli but showed markedly enlarged pulmonary arteries with normal peripheral vessels. Two independent HRCT specialists from different regions reviewed current and original HRCT/CTPA scans and agreed that the primary pattern was that of diffuse interlobular septal thickening (DIST) (fig 2) with no evidence of CWP or emphysema. Further review of his previous lung biopsy confirmed non-specific interstitial inflammation and fibrosis with no specific features of CWP. In view of these findings, other possible causes of DIST were actively excluded. Rectal biopsy showed no evidence of amyloidosis. Bronchoscopy showed anthracotic patches and diffuse telangiectasia throughout the bronchial tree (fig 3). The patient was too unwell for further lung biopsy and was referred urgently to a pulmonary hypertension unit. Unfortunately, he died before assessment. A post-mortem examination revealed lung fibrosis with areas of anthracotic pigment and anthracotic nodules as well as changes of pulmonary hypertension and right ventricular hypertrophy. The certified cause of death was "1a cor pulmonale, 1b coal workers' pneumoconiosis".

\section{DISCUSSION}

Diffuse interlobular septal thickening (DIST) is a pattern of lung disease found on high-resolution thoracic CT scanning (HRCT or CTPA). It represents pathology in the periphery of the pulmonary lobules (ie, the interlobular septa). This area is comprised of the pulmonary veins, capillaries and their associated interstitium. Conditions causing a predominant pattern of DIST include left ventricular failure, lymphangitis carcinomatosis, amyloidosis, pulmonary capillary haemangiomatosis (PCH), pulmonary veno-occlusive disease (PVOD) and pulmonary alveolar proteinosis. ${ }^{1} \mathrm{PCH}$ and $\mathrm{PVOD}$ are rare idiopathic conditions that obstruct either the pulmonary venules (in PVOD) or the alveolar capillaries (in $\mathrm{PCH}),{ }^{2}$ resulting in progressive pulmonary hypertension and death over several years. Both are characterised by DIST. Differentiating these entities from other causes of pulmonary hypertension and DIST is also critical as vasodilator therapy (used in primary pulmonary hypertension) can be harmful or fatal. ${ }^{1}$ Patients with $\mathrm{PCH}$ and PVOD have normal or restrictive spirometry with a falling transfer coefficient. ${ }^{3}$ Lung transplantation is currently the only means of improving prognosis.

DIST has not been reported in CWP. CWP is common $(12-50 \%)$ in those exposed to coal dust for more than 20 years. ${ }^{4}$ The coal dust particles are retained in the small airways and alveoli. Coal pigment (anthracosis) may be seen macroscopically (ie, on bronchoscopy) or microscopically (ie, on lung biopsy). The two recognised radiological patterns of CWP are simple pneumoconiosis (SP) and progressive massive fibrosis (PMF). ${ }^{5}$ However, $\mathrm{SP}$ is asymptomatic and has no effect on pulmonary function, ${ }^{6}$ although it may progress to PMF. ${ }^{7}$ 


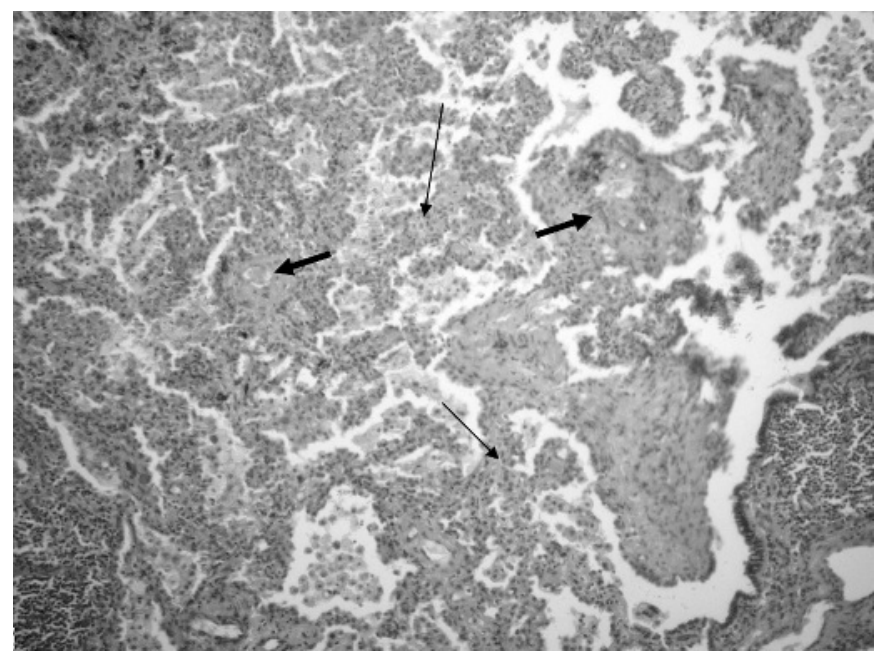

Figure 1 Lung biopsy (H\&E stain) showing interstitial thickening due to fibrosis and inflammation (thin arrows) and thickened pulmonary arteriolar walls (thick arrows).

PMF is progressive, with rounded masses of confluent fibrosis seen in the upper lobes of the lung. Spirometry shows a restrictive defect. ${ }^{8}$ However, if there is associated chronic obstructive pulmonary disease (COPD) related to coal dust, there may be an obstructive or a mixed spirometric defect.

This patient had a long history of coal exposure and was shown to have anthracosis on bronchoscopy but, surprisingly, had no typical features of CWP on HRCT/CTPA or lung biopsy. His spirometry showed mild obstruction, perhaps representing a mild degree of coal-induced COPD. However, a deteriorating carbon monoxide transfer coefficient (KCO) correlated with his clinical decline and subsequent death. The correlation with Kco suggests worsening lung parenchymal pathology rather than airways disease, with resultant severe secondary pulmonary

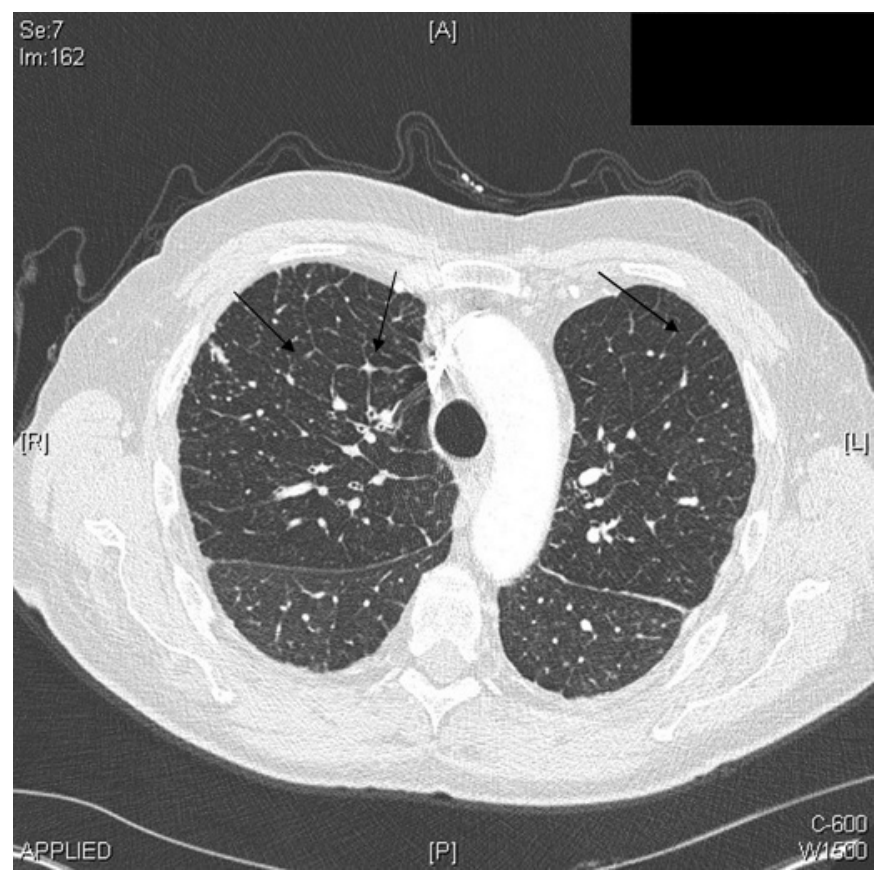

Figure 2 Thoracic CT-pulmonary angiography (CTPA) with arrows showing network of septal lines surrounding pulmonary lobules (ie, diffuse interlobular septal thickening).

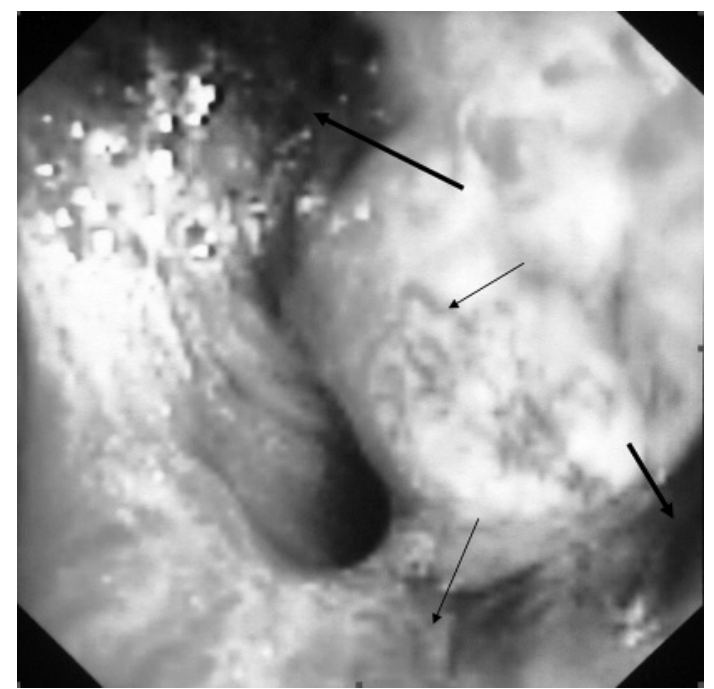

Figure 3 Bronchoscopic photograph (left lower lobe) showing areas of telangiectasia (thin arrows) and anthracosis (thick arrows).

hypertension (ie, cor pulmonale). The pattern of lung disease seen on HRCT/CTPA was DIST. We therefore excluded other possible causes of DIST and pulmonary hypertension. In particular, CTPA showed no evidence of pulmonary emboli and echocardiography showed no evidence of left ventricular failure. Lung biopsy excluded PCH and PVOD. The significance of the telangiectasia seen on bronchoscopy is unclear. Hereditary haemorrhagic telangiectasia is a condition that can be associated with pulmonary arteriovenous malformations and may cause pulmonary hypertension, though not DIST. Furthermore, this patient had no evidence of arteriovenous malformation on the echocardiogram, CT scan or on postmortem examination. He was eventually confirmed to have CWP at post-mortem examination, despite the atypical CT and biopsy findings.

In summary, this case highlights the importance of DIST as a pattern of interstitial lung disease on HRCT scanning and as a cause of fatal pulmonary hypertension. It is also the first description of such a pattern in coal workers. A possible "nodular" DIST pattern in CWP has been alluded to in the literature, ${ }^{10}$ although the cited paper identifies micronodular changes in the lung parenchyma and fissural areas rather than addressing DIST per se. ${ }^{11}$ Micronodularity can be missed on the HRCT scan, which seems to have been the case in this patient given the autopsy features. In view of these findings, we suggest that recognition of DIST is important in ensuring early and

Table 1 Lung function trend over time

\begin{tabular}{|c|c|c|c|}
\hline \multirow[b]{2}{*}{$\begin{array}{l}\text { Lung function test } \\
\text { results }\end{array}$} & \multicolumn{3}{|l|}{ Month/year } \\
\hline & $\begin{array}{l}\text { 11/1996 } \\
\text { (before steroids) }\end{array}$ & $\begin{array}{l}07 / 1997 \\
\text { (after steroid trial) }\end{array}$ & $\begin{array}{l}01 / 2008 \\
\text { (prior to death) }\end{array}$ \\
\hline $\mathrm{FEV}_{1}, \mathrm{I}$ (\% predicted) & $2.4(74 \%)$ & $2.1(71 \%)$ & $1.7(66 \%)$ \\
\hline FVC, I (\% predicted) & $3.9(103 \%)$ & $3.4(90 \%)$ & $3.3(87 \%)$ \\
\hline $\mathrm{FEV}_{1} / \mathrm{FVC}$ ratio & $62 \%$ & $62 \%$ & $52 \%$ \\
\hline TLC, I (\% predicted) & $\mathrm{N} / \mathrm{A}$ & $5.1(80 \%)$ & $5.9(94 \%)$ \\
\hline RV, I (\% predicted) & $\mathrm{N} / \mathrm{A}$ & $1.9(82 \%)$ & $2.4(90 \%)$ \\
\hline $\begin{array}{l}\mathrm{Kco} \mathrm{ml} / \mathrm{mm} \mathrm{Hg} / \mathrm{min} / \mathrm{l} \\
\text { (\% predicted) }\end{array}$ & $\mathrm{N} / \mathrm{A}$ & $3.3(63 \%)$ & $2.1(37 \%)$ \\
\hline
\end{tabular}

$\mathrm{FEV}_{1}$, forced expiratory volume in $1 \mathrm{~s}$; FVC, forced vital capacity; Kco, carbon monoxide transfer coefficient (transfer factor corrected for alveolar volume); $\mathrm{RV}$, residual volume; TLC, total lung capacity. 
accurate diagnostic pathways in interstitial lung disease, as well as early referral for lung transplantation.

Acknowledgements: The wife of our late patient who kindly supplied us with vital information for the article.

Competing interests: None.

Patient consent: Obtained from the patient's family.

Provenance and peer review: Not commissioned; externally peer reviewed.

\section{REFERENCES}

1. Ozsoyoglu AA, Swartz J, Farver CF, et al. High-resolution computed tomographic imaging and pathologic features of pulmonary veno-occlusive disease: a review of three patients. Curr Probl Diagn Radiol 2006;35:219-23.

2. Frazier AA, Franks TJ, Mohammed TL, et al. From the archives of the AFIP. pulmonary veno-occlusive disease and pulmonary capillary hemangiomatosis. Radiographics 2007;27:867-82.

3. Elliot CG, Colby TV, Hill T, et al. Pulmonary veno-occlusive disease associated with severe reduction of single-breath carbon monoxide diffusing capacity. Respiration 1988;53:262-6.
4. Soutar CA, Hurley JF, Miller BG, et al. Dust concentrations and respiratory risks in coalminers: key risk estimates from the British Pneumoconiosis Field Research. Occup Environ Med 2004;61:477-81.

5. International Labour Office (ILO). Guidelines for the use of the ILO international classification of radiographs of pneumoconiosis. Revised edition, 2000. Geneva: International Labour Office, 2002.

6. Maclaren WM, Hurley JF, Collins HP, et al. Factors associated with the development of progressive massive fibrosis in British coalminers: a case-contro study. Br J Ind Med 1989;46:597-607.

7. Hurley JF, Alexander WP, Hazledine DJ, et al. Exposure to respirable coalmine dust and incidence of progressive massive fibrosis. $\mathrm{Br} \mathrm{J}$ Ind $\mathrm{Med}$ 1987;44:661-72.

8. Soutar CA, Hurley JF. Relation between dust exposure and lung function in miners and ex-miners. Br J Ind Med 1986;43:307-20.

9. Cottin V, Plauchu H, Bayle J-Y, et al. Pulmonary arteriovenous malformations in patients with hereditary hemorrhagic telangiectasia. Am J Respir Crit Care Med 2004;169:994-1000.

10. Webb WR. Thin-section CT of the secondary pulmonary lobule: anatomy and the image - the 2004 Fleischner lecture. Radiology 2006;239:322-38.

11. Remy-Jardin M, Degreef JM, Beuscart R, et al. Coal worker's pneumoconiosis: CT assessment in exposed workers and correlation with radiographic findings. Radiology 1990;177:363-71.

\section{Lung alert}

\section{Identification of novel targets for COPD research using genome-wide association techniques}

Two recently published genome-wide association studies have highlighted the importance of large DNA databases in the identification of possible future targets for chronic obstructive pulmonary disease (COPD) therapy. The first study included over 7500 participants from the Framingham Heart Study. Four single nucleotide polymorphisms (SNPs) on chromosome 4 were found to be associated with a reduced $\mathrm{FEV}_{1} / \mathrm{FVC}$ ratio. The associated SNPs corresponded to a non-gene transcript area near the hedgehog-interacting protein (HHIP) gene. HHIP is a regulatory component in some cell signalling pathways involved in fetal development. The group were unable to explain the regulatory effect of the association but felt that the region warrants further investigation. In the second study 1600 patients with COPD and smoking controls from Norway were compared. Two SNPs at the $\alpha$-nicotinic acetylcholine receptor locus were found to be associated with lung function, and the association was confirmed by analysis in two other patient groups in the USA. The association with the HHIP area on chromosome 4 was replicated but did not reach genome-wide significance levels in this study.

Although COPD is thought to have a genetic predisposition, apart from $\alpha_{1}$-antitrypsin there is little information about the specific genes which underlie the disease. Genome-wide association studies can be problematic due to the potential for false positive results as a consequence of the number and power of the statistical tests performed. This is exemplified by the fact that, although HHIP has a role in the development of cartilage, nerves and has altered expression in various cancers, it has not yet been demonstrated to have a role in any pulmonary disorders. These studies can therefore be seen as "hypothesis generating". The problem is in translating statistically significant associations in genome studies into credible models of pathogenesis which allow development of clinically meaningful disease-specific therapies. The identification of an association of obstructive lung disease with a gene involved in fetal development in two independent studies is of interest and provides a target for future analysis.

- Wilk JB, Chen T, Gottlieb DJ, et al. A genome-wide association study of pulmonary function measures in the Framingham Heart Study. PLoS Genetics 2009;5:e1000429.

- Pillai SG, Ge D, Zhu G, et al. A genome-wide association study in chronic obstructive pulmonary disease (COPD): identification of two major susceptibility loci. PLoS Genetics 2009;5:e100421.

\section{Andrew B Hardy}

Correspondence to: Dr A B Hardy, Specialist Registrar, Huddersfield Royal Infirmary, Yorkshire, UK; andrewbhardy@yahoo.co.uk Thorax 2010;65:84. doi:10.1136/thx.2009.127415 